\section{ONOMAREDIN}

Revista semestral de lingüística, filología y traducción
PONTIFICIA UNIVERSIDAD CATÓLICA DE CHILE FACULTAD DE LETRAS

\title{
Tendencias actuales en los piropos españoles
}

Current trends in Spanish compliments

\author{
Dimitrinka G. Níkleva \\ Universidad de Granada \\ España
}

ONOMÁZEIN 34 (diciembre de 2016): 322-350

DOI: 10.7764/onomazein.34.19

\section{(c) $\odot$}

Dimitrinka G. Níkleva: Departamento de Didáctica de la Lengua y la Literatura, Facultad de Ciencias de la Educación, Universidad de Granada, España. | Correo electrónico: nikleva@ugr.es 
ONOMÁZEIN 34 (diciembre de 2016): 322-350

Dimitrinka G. Níkleva:

Tendencias actuales en los piropos españoles

\title{
Resumen
}

El presente estudio pretende detectar las tendencias actuales en los piropos españoles hechos tanto por hombres como por mujeres en una muestra de 224 piropos proporcionados por 40 participantes, estudiantes universitarios en la Universidad de Granada (Andalucía, España). Se estudia la frecuencia de los piropos más habituales. El análisis morfológico clasifica la muestra por categoría de palabras e incluye el vocabulario completo usado en la muestra junto a datos sobre el número de palabras, de palabras diferentes y la frecuencia de aparición de las palabras en el texto. Se determinan algunas características y recursos expresivos utilizados. El estudio confirma que el piropo es hiperbólico por naturaleza y que combina una amplia variedad de recursos expresivos. En los piropos de hombres la palabra más frecuente es bombón, seguida por guapa y sol, mientras que las mujeres prefieren guapo y bueno. En cuanto a la categoría gramatical, los hombres emplean más sustantivos, seguidos por pronombres, verbos y adjetivos en cuarta posición, a diferencia de las mujeres que se inclinan por los adjetivos en segundo lugar.

Palabras clave: piropos españoles; tendencias; frecuencia de vocabulario y de categoría de palabras.

\begin{abstract}
This study aims to detect the current trends in Spanish compliments and flirtatious remarks made both by women and men. A sample of 224 compliments and flirtatious remarks is examined, provided by 40 participants - university students from the University of Granada (Andalusia, Spain). We study the frequency of the most common compliments; carry out a morphological analysis of the sample by word category, and also analyse the complete vocabulary used in the sample, with the number of words and of different words, word appearance frequency in the text, included. Some characteristics and expressive resources utilized are determined. The study confirms that the compliment/flirtatious remark is by nature hyperbolic and combines a wide variety of expressive resources. In the men's compliments the most frequent word is "bombón" [stunner/gorgeous], followed by "guapa"
\end{abstract}


ONOMÁZEIN 34 (diciembre de 2016): 322-350

Dimitrinka G. Níkleva:

Tendencias actuales en los piropos españoles

[pretty] and "sol" [sweetie/darling], while the women prefer "guapo" [handsome/goodlooking] and "bueno" [good]. With regard to grammatical category, the men use more nouns, followed by pronouns, verbs and adjectives in fourth position, compared to the women, who favour adjectives more, being in second place.

Keywords: Spanish compliments and flirtatious remarks; trends; frequency of the vocabulary and word category. 
ONOMÁZEIN 34 (diciembre de 2016): 322-350

Dimitrinka G. Níkleva:

Tendencias actuales en los piropos españoles

\section{Introducción}

Esta investigación surge del interés en detectar las tendencias actuales y la moda en los piropos españoles, considerando que la lengua se encuentra en continuo desarrollo y todavía más en los aspectos pragmáticos, sociolingüísticos y léxicos.

Existen algunas investigaciones previas sobre el piropo y su evolución, pero sigue siendo un tema de actualidad, ya que está en continuo desarrollo. Presenta constantes cambios diacrónicos, diatópicos, diastráticos y diafásicos, o sea, cambia en el tiempo, según el lugar, en función de variables sociales y socioculturales de los hablantes, según el registro y el estilo, además de que conlleva diferencias en las distintas lenguas y culturas, en general.

Hay quienes opinan que hoy en día el piropo se encuentra en cierta decadencia debido al ritmo de la vida moderna y los cambios en las estrategias amorosas. Lanzar piropos poéticos resulta extemporáneo y casi ridículo. O eso temen los hombres. Si antes a la mujer se le comparaba con una flor, diosa, estrella, hoy se le compara con un tren ("Estás como un tren") o un ordenador como veremos a continuación. Parece que el piropo callejero va disminuyendo y se usan más medios como el móvil, el correo electrónico y las redes sociales.

Todo esto nos ha hecho pensar que conviene investigar sobre las tendencias actuales de los piropos españoles y observar qué características presentan hoy en día y en qué se diferencian de los piropos de antaño.

\section{Estudios precedentes}

\subsection{Origen del piropo}

En cuanto al origen del piropo, hay que destacar que Beinhauer (1978 [1929]) lo consideraba un género típicamente español, opinión que comparte también Diosdado (1996), que lo atribuye a los países de habla española. De hecho, en algunas lenguas resulta difícil traducir la palabra piropo, ya que disponen solo del cumplido o tienen una sola palabra para designar las dos acepciones. En inglés se usa solo la palabra compliment, pero 
ONOMÁZEIN 34 (diciembre de 2016): 322-350

Dimitrinka G. Níkleva:

Tendencias actuales en los piropos españoles

responde a 'cumplido'. Para diferenciar entre los dos conceptos se podría optar por traducir piropo como flirtation o flattering remark. En búlgaro, también se usa solo una palabra: комплимент [kompliment].

Algunos autores (Placencia y Yépez, 1999, citado por Calvo Pérez, 2005) consideran que el cumplido es común a las culturas anglosajona e hispana, mientras que el piropo es exclusivo de la hispana.

Preisig (1998: 39) plantea la pregunta de si los piropos pueden ser "restos de una gaya ciencia" de origen hispanoárabe, o sea, si tienen que ver con el amor cortés o el arte de los trovadores de la época de Al-Ándalus. Recordemos también que fue la modalidad andaluza de la lengua la que llegó al Nuevo Mundo, y los que la llevaron eran sevillanos de clase baja en su mayoría. Por eso, toda América Latina comparte con España y con Andalucía, en concreto, el arte del piropeo, a pesar de que en cada zona ha tenido unas características idiosincrásicas propias. En la misma línea se sitúa la observación de Nina Epton (1965), quien afirmaba que en Galicia y Cataluña los únicos hombres que piropeaban eran los inmigrantes andaluces.

\subsection{Principales enfoques en algunas investigaciones sobre el piropo en España}

Se puede afirmar que el interés hacia el piropo es tardío: se convirtió en objeto de estudio en el siglo XX. En un principio, la atención se centró en su morfología y estilística (Shreier, 2005) para pasar más tarde a sus valores y diferencias socioculturales en una lengua y cultura determinada, además de establecer comparaciones entre distintas lenguas y culturas.

Uno de los pioneros en los estudios del piropo español fue el hispanista alemán Beinhauer, que en 1929 expuso su visión romántica del piropo en un libro sobre el español coloquial. Los investigadores posteriores ampliaron los estudios e incluyeron también los piropos vulgares, burlescos y misóginos, estableciendo de esta manera dos tipos opuestos: uno alababa a la mujer y la ponía en un pedestal y el otro la denigraba. En este sentido, 
ONOMÁZEIN 34 (diciembre de 2016): 322-350

Dimitrinka G. Níkleva:

Tendencias actuales en los piropos españoles

coincidimos con Fridlizius (2009: 19), quien afirma que el piropo "siempre ha vivido entre el arte y la misoginia".

Entre los estudios precedentes hay que considerar también el de Calvo Pérez (2005), que es relativamente actual, ya que se centra en el piropo del 2000 en España. Define el piropo como "un acto de habla emotivo-compulsivo, metafórico e hiperbólico, que lanza creativamente el hombre a la mujer, casi siempre inesperadamente, produciéndole cierto rubor, por motivos de admiración determinados por la diferencia de sexo" (2005: 39).

En una perspectiva histórica y sociocultural se sitúa la tesis doctoral de Gabriela Preisig (1998) y los estudios de José Luis Calvo Carilla (2000).

Preisig estudia la etimología de la palabra piropo, los aspectos formales y funcionales del piropo, el perfil del piropeador (sus características sociales y psicológicas); elabora un análisis estilístico, apunta a la influencia del teatro castizo de los siglos XVIII, XIX y XX en el piropo y termina investigando las causas históricas y socioculturales de su decadencia.

Calvo Carilla (2000) dedica un extenso libro al piropo literario del siglo XX, en el que presenta la historia del piropo, tipos y situaciones en un recorrido por las obras literarias del siglo XX: de Arniches, Valle-Inclán, Francisco Nieva, Gutiérrez Solana, Ramón Gómez de la Serna y las greguerías en general, Benjamín Jarnés, André Breton, Pedro Muñoz Seca, Bécquer, Federico García Lorca, Camilo José Cela, entre otros. En otros términos, nos presenta el piropo en las obras de los modernistas y del esperpento, de los vanguardistas y de la generación del 27. Dedica también un capítulo al piropo en la España de Franco y en la obra de José Antonio Primo de Rivera. En la época de Franco los piropos reflejaban la escasez de comida, de calor o la falta de un hogar: "Con estos ojos tan negros, me río yo de la falta de carbón"; "Me gustas más, reina, que llevar bufanda en una noche de diciembre”; “¡Preciosa! Está usted más preciosa que un bocadillo en ayunas”. Eran frecuentes los piropos con Me gustas tanto como..., Me gustas más que... y seguían con alimentos como la fabada asturiana, el jamón serrano, la empanada gallega, el queso manchego o el pan con aceite (Venclovská, 2006: 12-13). Por tanto, podríamos afirmar que el piropo refleja los cambios lingüísticos y sociales. Por ejemplo, según Martín Gaite, las palabras guapo, majo y chulo inicialmente se consideraban como vulgares, pero al ser 
ONOMÁZEIN 34 (diciembre de 2016): 322-350

Dimitrinka G. Níkleva:

Tendencias actuales en los piropos españoles

imitadas en su uso por la clase alta, con el tiempo perdieron esta connotación y se convirtieron en piropos (Preisig, 1998: 80). Siguiendo con Calvo Carilla (2000: 59), hay que destacar que incluye también el graffiti amoroso como un nuevo tipo de piropo. El libro se cierra con el capítulo "La pintoresca visita de Nancy", donde se recogen y comentan los episodios relacionados con los piropos en la novela de Ramón J. Sender.

El humor en el libro de Calvo Carrilla convierte el libro en una lectura amena para un amplio púbico, no solo para el especializado. Se presenta el piropo como "un acto de sexo oral":

En resumen: puede decirse que el piropo era, inicialmente, una pasajera iniciativa de relación heterosexual que asumía el hombre en determinadas circunstancias. (El viejo Freud hubiera tenido mucho que decir sobre las oscuras motivaciones del deseo que subyacen incluso en la relación heterosexual más accidental e inocente). En este sentido, el piropo resultaba ser una manifestación unidireccional de sexualidad oral sub specie hiperbólica y elogiosa en la que, a la postre, no había esperanzas de correspondencia (como no la hay en ese "Chiquiya, eres tan alta que, para subir a darte un beso, hay que hacer noche en el ombligo": era absolutamente improbable que el tosco galán intentase tan arriscada ascensión) (Calvo Carrilla, 2000: 28).

Algunos investigadores como Malaver y González (2008) establecen la distinción entre piropo y contrapiropo y los estudian como un solo fenómeno de cortesía/descortesía verbal. En su estudio, el piropo es evaluado como una estrategia para reforzar la imagen positiva del emisor y de la destinataria, aunque también se puede interpretar como un acto descortés, puesto que obliga a la mujer a aceptar lo que un hombre desconocido dice públicamente de ella, en el caso de los piropos callejeros. Según estas autoras: "el piropo es una invasión a la intimidad y una agresión a la imagen negativa de la destinataria atenuada por el contenido; el antipiropo es una invasión a la intimidad y una agresión a la imagen negativa de la destinataria exacerbada por su contenido" (Malaver y González, 2008: 280).

Por último, querríamos mencionar también que el tema de los piropos resulta siempre interesante para los estudiantes extranjeros que dedican a los piropos españoles algunos de sus primeros trabajos de investigación (por ejemplo, Trabajos de Fin de Máster), como es el 
ONOMÁZEIN 34 (diciembre de 2016): 322-350

Dimitrinka G. Níkleva:

Tendencias actuales en los piropos españoles

caso de Venclovská (2006) en la República Checa, que estudia las características y los tipos de piropos, además de su evolución en España. Otro ejemplo es el trabajo de Fridlizius (2009) en Suecia, quien hace un estudio cualitativo sobre el uso actual de los piropos callejeros en España, diferenciándolos de los piropos escritos o de los que se hacen entre novios. Entre los objetivos de Fridlizius destaca el de comprobar si el piropo callejero está en extinción y si se ha convertido en una pura vulgaridad sin la capacidad seductora que tenía antaño.

\subsection{La decadencia del piropo}

Casi todas las investigaciones actuales sobre el piropo mencionan su decadencia hoy en día. La emancipación de la mujer parece que ha provocado la desaparición del piropo tradicional, que va acompañada de un incremento de las expresiones obscenas que algunas mujeres perciben como acoso sexual. Preisig le dedica un capítulo en el que expone como causas principales la emancipación de la mujer y las libertades conseguidas después de la época de Franco. Menciona también que hace tiempo era el teatro el que influía en el lenguaje de los piropos, pero que actualmente ha sido sustituido por la televisión y el cine. Hoy en día, el piropo se considera por muchos un juego infantil o un anacronismo social. También es cierto que muchos hombres ya no se atreven a practicarlo para no quedar en ridículo y por temer la reacción de la mujer. A pesar de que todavía no tenemos un museo del piropo, hay que reconocer que se encuentra en peligro de extinción.

Calvo Carrilla (2000: 21) alude también a "la muerte del piropo": "el piropo, tanto en su vertiente ofensiva como en la meramente laudatoria, está muerto en este agonizante fin de siglo y tan sólo algunas anacrónicas convocatorias para internautas desocupados recogen hoy bajo ese nombre insulsas declaraciones amorosas”.

Ya en los años 60 se avisaba sobre este abandono de la palabra para pasar a los hechos. El hacer empezaba a cobrar protagonismo en detrimento del cortejar. 
ONOMÁZEIN 34 (diciembre de 2016): 322-350

Dimitrinka G. Níkleva:

Tendencias actuales en los piropos españoles

\subsection{Los piropos informáticos}

En esta misma línea de los internautas y sus declaraciones amorosas mencionadas anteriormente se sitúa el estudio de una profesora universitaria rusa —Zvereva (2014)—, escrito en ruso y enfocado en los piropos informáticos entre los piropos españoles. A continuación ofrecemos algunos de sus ejemplos (los menos complicados terminológicamente):

quisiera ser teclado para que me tocaras

tus ojos brillan más que mi torre de $C D$

tu voz es más sexy que los sonidos de 8-bits

quisiera ser página web para que me agregaras a tus favoritos

ojalá fuera blog para que me visitaras

desearía ser mouse para que me muevas

quisiera ser un pendrive para tu USB

jugamos al código binario, tú pones el 0 y yo te pongo el 1

sin ti mi sistema operativo entra en hibernación

si me dejas hago Alt-F4 a mi vida [...me elimino...daría el comando de eliminación]

tienes más estilo que W3C y más caché que Google

tu corazón.com está en mi página WEB

mi MacOSC tiene envidia de tu belleza

ninguna gráfica podría renderizar a 100\% tu perfecta figura

Consideramos que este tipo de piropos resulta ser una clara muestra de que los piropos son un espejo de la sociedad y reflejan los cambios lingüísticos y sociales, como seguiremos comprobando en este estudio.

\section{Características del piropo}

Existen varias clasificaciones de los piropos según el tema predominante, la parte del cuerpo alabada, según variantes diatópicas (por ejemplo, los piropos andaluces), 
ONOMÁZEIN 34 (diciembre de 2016): 322-350

Dimitrinka G. Níkleva:

Tendencias actuales en los piropos españoles

diastráticas o diafásicas, según el género literario, según la estructura sintáctica o el uso reiterativo de una palabra determinada. Por supuesto, el piropo varía de una lengua y cultura a otra y por eso hay que conocer también las diferencias pragmáticas, sociolingüísticas y socioculturales que presenta.

El piropo comparte algunas de las características de los cumplidos y los requiebros y presenta otras propias y específicas:

- Sentido del humor, ingenio.

- Agilidad verbal.

- Imaginación y originalidad.

- Creación espontánea.

- Producto de la voluntad propia del emisor (frente al cumplido que forma parte de las reglas de buen comportamiento y, por tanto, resulta socialmente obligatorio en determinadas circunstancias).

- Fórmula breve, a veces rimada.

- Uso de recursos expresivos y tropos como la metáfora, la hipérbole, preguntas retóricas, entre otros.

- Encierra a menudo actitudes machistas.

- A menudo se dice en grupo, ya que responde a la necesidad de impresionar a los amigos y proporciona poder en el grupo.

- Tendencia al exhibicionismo y al narcisismo.

- Según la época, ha sido expresión de la sexualidad reprimida del hombre.

- No requiere necesariamente respuesta, pero se puede agradecer o devolver el piropo (contrapiropo) a diferencia del cumplido por el que normalmente se dan las gracias.

- Se suele decir en la calle a una mujer desconocida, aunque hoy en día las mujeres piropean también cada vez más.

- Combina varias funciones del lenguaje: lúdica, expresiva, representativa, apelativa y poética. 
ONOMÁZEIN 34 (diciembre de 2016): 322-350

Dimitrinka G. Níkleva:

Tendencias actuales en los piropos españoles

- Tiene múltiples escenarios: la calle, una obra de construcción (sigue siendo el tópico más divulgado), discotecas, pubs, fiestas, el automóvil (se llega a hablar del piropo automovilístico, lanzado desde un coche en movimiento), en situación de paso, en fin, cualquier lugar.

- Presenta diferentes estilos: existen piropos poéticos, románticos, obscenos (verdes), vulgares y ordinarios.

- Se centra en la belleza femenina, en partes del cuerpo (pecho, ojos, trasero, cara, pelo), en cuestiones sexuales, en la ropa, a veces en el andar; no existen piropos sobre el carácter ni las habilidades intelectuales de la gente.

- Puede ser un gesto o una mirada: los hidalgos españoles arrojaban la capa ante el paso de la dama deseada o los hombres en el siglo XIX se tapaban los ojos delante de una mujer hermosa en señal de que podían ser hechizados por ella.

- Puede consistir en un silbido (o el silbido puede acompañar el piropo).

- Con frecuencia el enfado de la mujer piropeada es fingido.

- Teatralidad (la calle es la escena y la gente, el público).

- Les suele gustar a los piropeados, ya que sube la autoestima, pero gustan los piropos respetuosos y elaborados con buen gusto, no los obscenos.

Como se ha observado, el piropo puede ser no verbal: una mirada, un gesto, un silbido o el claxon tocado desde un coche (en el caso del piropo automovilístico). En cuanto a la mirada, interpretada como piropo, cabe mencionar a López de Haro (1953) y su novela Piropo, donde denomina "piropo mental" a la mirada. En la misma línea se sitúa El sexo de nuestros padres de Juan Eslava Galán, que llega a considerar "coito visual al acto de penetrar con la mirada a una mujer" (citado por Preisig, 1998: 27). El autor explica su opinión con "la represión sexual del típico macho español que solía lanzar piropos y miradas provocativas porque necesitaba afirmar su hombría a cada paso". Añade: "las calles de España están llenas, a sus horas, de miradas que se eclipsan, se cruzan, se besan o se acometen como floretes sutiles" (El sexo de nuestros padres, citado por Preisig, 1998: 
ONOMÁZEIN 34 (diciembre de 2016): 322-350

Dimitrinka G. Níkleva:

Tendencias actuales en los piropos españoles

28). Hay que tener en cuenta que en ocasiones el piropo era la respuesta a la mirada provocadora de una mujer que, en este caso, no se limitaba a un papel pasivo.

Según Preisig (1998: 103), el piropo "permitía establecer un contacto fugaz con el otro sexo y proporcionaba un vago placer erótico". Hay que reconocer que a veces solo el sentido del humor hace que el piropo no parezca acoso sexual: "Niña, ¿no sabes que la virginidad es una enfermedad y que en esta esquina se cura?" (Enríquez, 1991, citado por Preisig, 1998: 16).

Por último, nos parece interesante y necesario incluir la opinión de Francisco Umbral (1970, citado por Beinhauer, 1973: 166) quien considera que el piropo es un género literario y que su función principal no es la erótica. Está convencido de que el piropeador pretende, en primer lugar, lucir su talento literario, su imaginación y creatividad.

\section{Objetivos de la investigación}

Nuestro estudio pretende conseguir los siguientes objetivos:

1) Detectar las actuales tendencias predominantes en los piropos españoles.

2) Estudiar la frecuencia de los piropos más habituales.

3) Estudiar la frecuencia de las categorías gramaticales en la muestra de piropos.

4) Observar las diferencias según la variable sexo.

5) Observar la frecuencia del vocabulario más usado en los piropos.

\section{Metodología}

\subsection{Participantes}

Los participantes en el estudio son 40 estudiantes universitarios de la Universidad de Granada (España) de la titulación de Audición y Lenguaje en 2009 ( $2^{\circ}$ curso), en la Facultad de Ciencias de la Educación. Predominan las mujeres, con un 87,5 \% (35), frente a 12,5\% (5). La edad de los participantes oscila entre 19 y 36, siendo la moda de 19. 
ONOMÁZEIN 34 (diciembre de 2016): 322-350

Dimitrinka G. Níkleva:

Tendencias actuales en los piropos españoles

\subsection{Instrumentos de recogida de datos}

El instrumento de la investigación consiste en un cuestionario de 14 preguntas abiertas, todas ellas variables nominales, sin contar las variables de edad y sexo. El cuestionario se puede consultar en el Anexo. Para su elaboración nos hemos basado en el estudio de Calvo Pérez (2005).

Las respuestas del cuestionario nos han proporcionado una muestra de 224 piropos en total, hechos por hombres y mujeres.

\subsection{Métodos de análisis utilizados}

Para el análisis hemos dividido la muestra de 224 piropos en dos grupos:

1) Piropos que hacen los hombres (151).

2) Piropos que hacen las mujeres (73).

Nos ha parecido oportuno dividir la muestra según el sexo de los participantes para poder investigar las posibles diferencias que se originan en función de esta variable.

Para nuestro estudio nos planteamos un análisis cuantitativo. Para ello usaremos dos herramientas informáticas: el programa SPSS 21 y el Parametrizador Morfológico de Textos (el ParamText TIP) (Carreras-Riudavets y otros, 2011).

Con el ParamText TIP analizamos el contenido morfológico y léxico de la muestra. Además, incluimos el número de palabras y de palabras diferentes, la frecuencia de aparición de las palabras en el texto, la distribución de las palabras según su primera aparición en el texto, el centro de gravedad (la media de posiciones en las que aparece dicha palabra en el texto que, por tanto, proporciona una idea de la zona del texto en la que más o menos aparece dicha palabra con más frecuencia) y su frecuencia de uso en el español (en un amplio corpus que ofrece la herramienta). Asimismo, nos permite mostrar en una tabla el vocabulario completo utilizado en el texto. Proporcionamos también un análisis morfológico de la muestra por categoría de palabras. 
ONOMÁZEIN 34 (diciembre de 2016): 322-350

Dimitrinka G. Níkleva:

Tendencias actuales en los piropos españoles

\section{Análisis de datos y discusión de resultados}

En el análisis de los datos que aquí se presenta incluimos los resultados que consideramos más relevantes para los objetivos de esta investigación y, por consiguiente, que querríamos destacar.

Los mayoría de los participantes (73\%) coincide en que antes los piropos eran más románticos, poéticos, respetuosos, mientras que en la actualidad son habituales los ordinarios, los groseros, verdes y obscenos. La mayoría $(61,1 \%)$, tanto las mujeres como los hombres, reconoce que sí le gustan los piropos, pero los bonitos y no los groseros. No hacía esta distinción la inglesa Nina Epton, quien decía: "para una extranjera, uno de los más molestos rasgos del español que hace que viajar por España resulte enojoso (aunque menos que en Italia) es su actividad ocular, unida a la irritante costumbre del piropo (1965, citado por Preisig, 1998: 42). Posiblemente resulte curioso el hecho de que en la primera mitad del siglo XX el general Primo de Rivera (1923-1930) prohibió el uso de los piropos en la calle por considerarlos vulgares (Fridlizius, 2009).

En cuanto a la edad, los participantes en el estudio consideran que la del piropeado se sitúa entre la adolescencia y los 30-40 años (42,5\%) y otro $10 \%$ opina que es la misma que del piropeador, que, a su vez, según los porcentajes más altos en las respuestas, puede tener cualquier edad (25\%) o ser adolescente, joven o mayor (25\%). Un 15\% incluye también a los ancianos (junto con los jóvenes) entre los piropeadores. Algunas de las opiniones de los sujetos son: "aproximadamente la misma que el piropeado"; "desde pequeños, pero es diferente la forma de piropear y la intención"; "desde 15 hasta la muerte"; "mayor que el piropeado". En este sentido, nuestro estudio confirma los resultados de otras investigaciones previas (Calvo Pérez, 2005, Preisig, 1998, Andrews, 1977), donde se afirma que el piropeador puede tener cualquier edad, pero en general se sitúa entre los $15 \mathrm{y}$ los 35 años y que un hombre mayor que echa piropos corre el peligro de parecer un "viejo verde".

Otra cuestión es: ¿quién piropea a quién? Quizás una de las tendencias más relevante consiste en que hoy en día piropean tanto los hombres como las mujeres, aunque las 
ONOMÁZEIN 34 (diciembre de 2016): 322-350

Dimitrinka G. Níkleva:

Tendencias actuales en los piropos españoles

mujeres no lanzan piropos a un desconocido en la calle (o lo hacen menos y solo en grupo), sino que los reservan para un ámbito más íntimo. El 90\% responde que normalmente es el hombre quien piropea a la mujer. El 7,5\% considera que hoy en día piropean tanto los hombres como las mujeres.

En cuanto al lugar donde se piropea, el 70\% responde que en la calle, discotecas, bares, parques y andamios. E1 22,5\% considera que en cualquier sitio.

Los resultados de la pregunta sobre la situación en la que se piropea indican que en cualquier situación $(31,4 \%)$, para ligar $(20 \%)$ y en ambientes festivos $(11,4 \%)$. Solo un participante (mujer de 25 años) ha señalado la intimidad como espacio donde se producen también piropos. La misma participante señala como situación más típica en que se produce o se espera un piropo la "situación de amor". En este último aspecto, la respuesta que predomina entre el resto de los 39 participantes es "obras y albañiles" (32,5\%), que es todo un tópico en España como el sitio más habitual en que a una mujer le echan piropos. En segundo lugar sitúan las "discotecas, pubs y fines de semana” (25\%). Tres de los sujetos de nuestro estudio aluden a una situación convertida en tópico y presente en casi todas las investigaciones sobre el piropo, obras y albañiles, algo que viene a confirmar que el piropo pertenece a las clases humildes que consideran la calle su territorio.

Ya en el año 1921, Beinhauer destacaba el origen plebeyo del piropo y afirmaba que “el piropo crece sobre el más amplio terreno de la sociedad española”, pero especificaba que son "las capas inferiores y aun las más ínfimas [...] las que mejores condiciones muestran para el ejercicio de este arte" (citado por Preisig, 1998: 44-45). La misma opinión expresa mucho más tarde David Enríquez, que en 1991 elabora una antología de piropos chilenos, donde observa, entre otros aspectos, que "las clases ilustradas y acomodadas del país no ostentan una tradición piropera" (1991: 7). Preisig (1998: 45) recoge otro ejemplo sobre la idea clasista del piropo en la obra de los hermanos Joaquín y Serafín Álvarez Quintero, creadores del teatro popular andaluz: "en Los piropos una muchacha de la clase burguesa se pasea delante de dos pueblerinos esperando ávidamente que le echen un piropo. Dice para sí: “A ver si me disen algo; porque los niños de nuestra clase son de lo más 
ONOMÁZEIN 34 (diciembre de 2016): 322-350

Dimitrinka G. Níkleva:

Tendencias actuales en los piropos españoles

patoso". Le gustaría que a su novio le ocurriesen cosas graciosas como las que salen de la boca de estos dos rústicos".

Normalmente, a las mujeres les gusta recibir piropos. Así lo confirman las participantes en nuestro estudio, pero aclaran que se refieren a los piropos de buen gusto y no a los ordinarios. Tal como cuenta Preisig (1998: 102): “en la época de nuestros abuelos se decía que si una mujer se paseaba por la Gran Vía de Madrid sin que le echasen un piropo, debía ser más fea que el demonio".

En cuanto a los hombres que todavía echan piropos, recogemos otro ejemplo de Preisig (1998: 47): “Un taxista madrileño me dijo que le encanta llamar guapa a las guapas y también a las feas porque así se ponen contentas. Su intención es agradar y devolver el placer que le causa la vista de una mujer".

Por cierto, hemos comprobado que esta muletilla y el uso de "guapa" como vocativo ocasionan con frecuencia serios malentendidos para hablantes no nativos del español. Dicho de otra manera, algunas se lo creen al pie de la letra y les provoca un subidón de ánimo, cercano a la felicidad, que no tiene nada que ver con la realidad.

Después del análisis de las preguntas de opinión, a continuación presentamos los piropos que se repiten con mayor frecuencia en la muestra obtenida por orden de frecuencia:

\section{1) En los piropos hechos por hombres:}

- Niña, vete por la sombra que los bombones al sol se derriten (17 veces) (otras versiones: Tira por la sombra que los bombones al sol se derriten).

- Se te ha caído el papel que te envolvía, bombón (9 veces).

- ¡Guapa! (8 veces).

- ¡Que no me entere yo que ese culo pasa hambre! (7 veces).

- Tu madre debía ser pastelera porque un dulce como tú no lo fabrica cualquiera (5 veces) (otras versiones: Tu padre será panadero, porque un bombón como tú no lo hace cualquiera). Una versión búlgara de este piropo sería: Madre artista y padre pintor. 
ONOMÁZEIN 34 (diciembre de 2016): 322-350

Dimitrinka G. Níkleva:

Tendencias actuales en los piropos españoles

- Tía buena, maciza, tu culo me hipnotiza (4 veces).

Querríamos destacar, lamentablemente, que solo uno de los sujetos ha escrito correctamente el verbo hipnotiza. Lo encontramos dos veces como 'innotiza' y una vez sin $h$ 'ipnotiza'.

\section{Ejemplos de piropos más elaborados ("poéticos"):}

- El día que naciste hubo una lluvia de estrellas y en tu casa cayó la más bonita de ellas.

- Si Dios existe tú eres su creación.

- Eres el alimento de mi alma.

- ¡Guapa!, que la luna te envidia cuando sale.

- En mi mundo el día no existe hasta que no te veo.

- Aunque solo me quedase un segundo de vida solo querría mirarte a ti.

- Más guapa que el sol.

- Me gustaría ser lágrima para nacer en tus ojos, rozar tus mejillas y morir en tus labios.

- Tus ojos son como la miel.

- Eres un ángel caído del cielo.

- Si hoy no es fiesta, ¿por qué está la Virgen en la calle?

- Tendrías que ser patrimonio de la humanidad.

- Perdona, ¿dónde están tus alas? Nunca había visto un ángel sin ellas.

- ¡Qué puerta se habrá quedado abierta en el cielo que hoy está todo lleno de ángeles!

- Si fuera 20 años más joven, intentaría enamorarte.

- Sonreír es la segunda cosa que se puede hacer con tus labios.

- Eres una rosa.

- Si la belleza fuese pecado, estabas condenada. 
ONOMÁZEIN 34 (diciembre de 2016): 322-350

Dimitrinka G. Níkleva:

Tendencias actuales en los piropos españoles

\section{Ejemplos de piropos obscenos (verdes, ordinarios):}

Los autores que hemos consultado discrepan en cuanto a los piropos obscenos. Unos opinan que no hay que considerarlos como piropos, pero predominan lo que no los descartan, a pesar de calificarlos como groseros o insultantes (Calvo Pérez, 2005). Hemos optado por presentar ejemplos de este grupo, ya que los incluyen los sujetos participantes en nuestra investigación, por tanto, consideramos que representan una de las tendencias actuales, que por no mencionarla, no desaparecería.

- Te la metía y no te la sacaba hasta que me mordiera el niño.

- Te rellenaba el agujero del cemento del bueno.

- ¡Niña, que estás tan buena que te comía la regla a “cucharás”!

- Estás tan buena que te comía y me cosía el culo pa' no cagarte.

- Tienes ojos que te comía todo el coño.

- Te metía una naranja en la boca y te exprimía hasta que echaras fanta.

- Te compraba un castillo y un manicomio. Un castillo para que vivieras como una reina y un manicomio para follar como locos.

- Si el amor te da la espalda, tócale el culo.

- ¿Jugamos al teto? Tú te agachas y yo te la meto.

- Niña, como pisas no te la meto porque llevo prisa.

- Te voy a comer hasta la gomilla de las bragas.

Otros ejemplos de la muestra de piropos de los hombres:

- ¡Eso es un cuerpo y no el de la Guardia Civil! (en otras versiones: de la policía, de bomberos).

- ¡Estás más apretada que las tuercas de un submarino!

- Tienes más delantera que el equipo del Real Madrid.

- Si paseas por la torre de Pisa ; hasta ella se endereza!

- Eso es carne y no lo que le echa mi madre al cocido. 
ONOMÁZEIN 34 (diciembre de 2016): 322-350

Dimitrinka G. Níkleva:

Tendencias actuales en los piropos españoles

- Dime quién fue tu arquitecto para contratarlo para mi casa.

- Cuerpo escándalo.

- Te comía a bocados.

- Te comía del bollicado hasta la pegatina.

2) En los piropos hechos por mujeres:

- ¡Guapo! (con versiones: Guapísimo, Guapazo, ¡Qué guapo que estás! (15 veces).

- ¡Tío bueno! o ¡Qué bueno que estás! (7 veces).

\section{Ejemplos de piropos más elaborados ("poéticos"):}

- Si cada vez que pensara en ti una estrella se apagara, no habría en el cielo una estrella que brillara.

- Que sueñes con los angelitos que yo soñaré contigo.

- Tienes unos ojos como dos luceros.

- ¿Qué ojazos! Me perdería en ellos toda la noche.

- Eres más guapo que el sol.

- Eres un cielo / cielín.

- Tienes los ojos más bonitos del mundo.

\section{Ejemplos de piropos obscenos en la muestra de piropos hechos por las mujeres:}

Conviene precisar que todos los ejemplos en este subgrupo pertenecen a una sola participante en la investigación. Por consiguiente, la mayoría de las mujeres no hacen piropos obscenos.

- ¡Mozo! Me apeteces pa' esta noche.

- Juro que con este culito ijamás volvería a pasar hambre!

- El de rojo... que te la cojo.

- Te comía hasta con ropa aunque me tirara un mes cagando trapos. 
ONOMÁZEIN 34 (diciembre de 2016): 322-350

Dimitrinka G. Níkleva:

Tendencias actuales en los piropos españoles

\section{Otros ejemplos de la muestra de piropos de las mujeres:}

- Me gustas más que comer con los dedos.

- ¡Macizorro!

- ¡Quiero un hijo tuyo!

- ¡Ay, omá, qué rico!

- Eso es un cuerpo y no el de policía.

- Collejo.

Antes de iniciar el análisis morfológico y léxico de la muestra, presentamos la tabla 1, que incluye el número de piropos, de palabras y de palabras diferentes, según el sexo de los participantes en el estudio.

Tabla 1. Número de piropos, número de palabas en total y de palabras diferentes según la variable sexo

\begin{tabular}{|l|r|r|}
\hline & \multicolumn{1}{|c|}{ Piropos } & \multicolumn{2}{c|}{$\begin{array}{c}\text { Piropos } \\
\text { hechos por hombres }\end{array}$} & 73 \\
\hline Número total de piropos & 151 & 327 \\
\hline Palabras en total & 1209 & 169 \\
\hline Palabras diferentes & 380 & heres \\
\hline
\end{tabular}

El análisis morfológico del corpus de los piropos de los hombres (tabla 2 y gráficos 1 y 2) revela que en el caso de los hombres predominan los sustantivos (716), seguidos por los pronombres (342) y los verbos (338), mientras que las mujeres usan en segundo lugar los adjetivos (104).

Tabla 2. Frecuencia de la categoría gramatical según la variable sexo

\begin{tabular}{|l|r|r|}
\hline \multirow{2}{*}{ Categoría gramatical } & \multicolumn{2}{|c|}{ Frecuencia } \\
\cline { 2 - 3 } & Hombres & Mujeres \\
\hline Sustantivos & 716 & 197 \\
\hline
\end{tabular}


ONOMÁZEIN 34 (diciembre de 2016): 322-350

Dimitrinka G. Níkleva:

Tendencias actuales en los piropos españoles

\begin{tabular}{|l|r|r|}
\hline Pronombres & 342 & 101 \\
\hline Verbos & 338 & 81 \\
\hline Adjetivos & 292 & 104 \\
\hline Adverbios & 145 & 53 \\
\hline Artículos & 136 & 33 \\
\hline Conjunciones & 158 & 35 \\
\hline Preposiciones & 106 & 20 \\
\hline No reconocidas & 4 & 5 \\
\hline No reconocidas (sin repetición) & 4 & 4 \\
\hline
\end{tabular}

En cuanto a la categoría gramatical, los hombres emplean más sustantivos, seguidos por pronombres, verbos y adjetivos en cuarta posición, a diferencia de las mujeres que se inclinan por los adjetivos en segundo lugar. El orden usado por las mujeres es: sustantivos, adjetivos, pronombres, verbos.

Para los objetivos de nuestro estudio nos interesa analizar también el vocabulario usado, según la frecuencia de cada palabra (tablas 3 y 4).

Tabla 3. Frecuencia del vocabulario en los piropos hechos por hombres (solo sustantivos, verbos y adjetivos)

\begin{tabular}{|l|r|r|r|r|r|}
\hline \multicolumn{1}{|c|}{ Palabra } & $\begin{array}{r}\text { Frecuenci } \\
\text { a (texto) }\end{array}$ & $\begin{array}{r}\text { Primera } \\
\text { aparición }\end{array}$ & $\begin{array}{r}\text { Centro de } \\
\text { gravedad }\end{array}$ & $\begin{array}{c}\text { Desviació } \\
\text { n típica }\end{array}$ & $\begin{array}{c}\text { Frecuencia } \\
\text { (corpus) }\end{array}$ \\
\hline bombón/bombones & 28 & 56 & 805 & 420,36 & 181 \\
\hline guapa & 20 & 10 & 670 & 419,23 & 2646 \\
\hline sol/soles & 17 & 27 & 618 & 392,13 & 80865 \\
\hline tener (formas flexivas) & 14 & 430 & 648 & 154,2 & 46750 \\
\hline culo & 13 & 5 & 533 & 346,69 & 3009 \\
\hline sombra & 12 & 106 & 539 & 370,76 & 38306 \\
\hline derriten & 12 & 116 & 534 & 349,85 & 107 \\
\hline buena & 11 & 2 & 512 & 442,03 & 93067 \\
\hline ha & 11 & 14 & 447 & 412,95 & 735916 \\
\hline caído & 11 & 15 & 407 & 408,37 & 16570 \\
\hline
\end{tabular}


ONOMÁZEIN 34 (diciembre de 2016): 322-350

Dimitrinka G. Níkleva:

Tendencias actuales en los piropos españoles

\begin{tabular}{|l|r|r|r|r|r|}
\hline papel & 10 & 19 & 491 & 449,15 & 52629 \\
\hline ojos & 10 & 119 & 505 & 334,51 & 231052 \\
\hline eres & 9 & 240 & 582 & 307,77 & 55892 \\
\hline madre & 8 & 98 & 436 & 367,08 & 122000 \\
\hline envuelve & 8 & 22 & 579 & 463,74 & 2261 \\
\hline comía & 8 & 85 & 480 & 292,91 & 4138 \\
\hline hambre & 8 & 207 & 737 & 298,33 & 23127 \\
\hline tia & 7 & 1 & 398 & 400,28 & 17990 \\
\hline ser & 6 & 127 & 559 & 379,66 & 543430 \\
\hline entere & 5 & 201 & 697 & 370,26 & 993 \\
\hline ve/vete & 5 & 103 & 260 & 147,31 & 56459 \\
\hline ángel/ángeles & 5 & 242 & 341 & 112,93 & 12650 \\
\hline morena/morenaza & 5 & 294 & 605 & 317,54 & 703 \\
\hline hipnotiza & 4 & 7 & 581 & 412,39 & 46 \\
\hline derrites & 4 & 30 & 498 & 536,52 & 22 \\
\hline echa & 4 & 100 & 330 & 162,36 & 8332 \\
\hline bonitos & 4 & 166 & 486 & 277,29 & 1281 \\
\hline pastelera & 4 & 128 & 624 & 448,07 & 59 \\
\hline pase & 3 & 659 & 865 & 199,8 & 10722 \\
\hline maciza & 3 & 245 & 371 & 195,65 & 99431 \\
\hline cielo & 3 & & & & 504,38 \\
\hline
\end{tabular}

Entre las palabras que hemos omitido abundan los pronombres personales de primera y segunda persona. Se usa diez veces la palabra más y tres veces, olé.

Queremos destacar también algunas palabras que aparecen solo una vez en la muestra de los piropos hechos por hombres: amor, alma, estrella, lágrima, morir.

En la tabla anterior se comprueba que la palabra que aparece con mayor frecuencia es bombón. Para contextualizarla recordamos los piropos más frecuentes en la muestra que la incluyen:

- Niña, vete por la sombra que los bombones al sol se derriten (17 veces) (Otras versiones: Tira por la sombra que los bombones al sol se derriten). 
ONOMÁZEIN 34 (diciembre de 2016): 322-350

Dimitrinka G. Níkleva:

Tendencias actuales en los piropos españoles

- Se te ha caído el papel que te envolvía, bombón (9 veces).

La misma palabra, "bombón”, aparece también en los ejemplos de piropos en forma dialogada que se repiten con mayor frecuencia en la muestra:

1) - Se te ha caído.

- ¿El qué?

-El papel que te envolvía, bombón.

2) - ¿Tu madre era pastelera?

- ¿Por qué?

- Porque un bombón como tú no lo hace cualquiera.

Los ejemplos anteriores presentan versiones distintas en la muestra, pero varían ligeramente, por lo que no los hemos considerado como piropos distintos. Los hemos seleccionado porque son de los más usados en la muestra recogida.

Tabla 4. Frecuencia del vocabulario en los piropos hechos por mujeres (selección de solo sustantivos, verbos y adjetivos)

\begin{tabular}{|l|r|r|r|r|r|}
\hline \multicolumn{1}{|c|}{ Palabra } & \multicolumn{1}{|c|}{$\begin{array}{c}\text { Frecuencia } \\
\text { (texto) }\end{array}$} & \multicolumn{1}{c|}{$\begin{array}{c}\text { Primera } \\
\text { aparición }\end{array}$} & $\begin{array}{c}\text { Centro de } \\
\text { gravedad }\end{array}$ & $\begin{array}{c}\text { Desviación } \\
\text { típica }\end{array}$ & \multicolumn{1}{c|}{$\begin{array}{c}\text { Frecuencia } \\
\text { (corpus) }\end{array}$} \\
\hline $\begin{array}{l}\text { guapo/guapazo/ } \\
\text { guapetón/guapísimo }\end{array}$ & 17 & 1 & 134 & 119,48 & 2932 \\
\hline bueno & 9 & 3 & 110 & 84,75 & 88122 \\
\hline eres & 6 & 23 & 157 & 102,7 & 55892 \\
\hline estás & 5 & 4 & 74 & 58,77 & 44864 \\
\hline tio & 5 & 57 & 142 & 88,81 & 32340 \\
\hline bombón/es & 3 & 15 & 15 & 0 & 181 \\
\hline ojazos/ojos & 7 & 66 & 224 & 137,5 & 309 \\
\hline tienes/tiene & 7 & 266 & 281 & 21,92 & 46750 \\
\hline comer (formas flexivas) & 5 & 107 & 216 & 95,57 & 0 \\
\hline macizo / macizorro & 3 & 56 & 56 & 0 & 1862 \\
\hline sol & 3 & 94 & 199 & 93,56 & 80865 \\
\hline
\end{tabular}


ONOMÁZEIN 34 (diciembre de 2016): 322-350

Dimitrinka G. Níkleva:

Tendencias actuales en los piropos españoles

\begin{tabular}{|l|r|r|r|r|r|}
\hline hambre & 2 & 156 & 241 & 120,21 & 23127 \\
\hline cielo & 2 & 160 & 184 & 33,94 & 99431 \\
\hline vaya & 2 & 116 & 205 & 126,57 & 36488 \\
\hline culo & 2 & 265 & 280 & 21,92 & 3009 \\
\hline luceros & 2 & 219 & 252 & 47,38 & 729 \\
\hline moreno & 1 & 119 & 119 & 0 & 7085 \\
\hline comía & 1 & 165 & 165 & 0 & 4138 \\
\hline hasta & 1 & 166 & 166 & 0 & 481152 \\
\hline comer & 1 & 277 & 277 & 0 & 37335 \\
\hline
\end{tabular}

Entre las palabras que hemos omitido destaca el uso repetitivo de más (7 veces).

¿Pero cómo se usan las palabras que hemos obtenido con el análisis anterior? ¿Cómo se combinan y qué efecto consiguen? El piropo es hiperbólico por naturaleza. Muchos son rimados. En general, se usan muchos recursos literarios o estilísticos que ejemplificamos en la tabla 5 .

Tabla 5. Recursos expresivos en los piropos

\begin{tabular}{|l|l|}
\hline \multicolumn{1}{|c|}{ Recurso expresivo } & \multicolumn{1}{|c|}{ Ejemplo } \\
\hline Hipérbole & En mi mundo el día no existe hasta que no te veo \\
\hline \multirow{5}{*}{ Rima } & $\begin{array}{l}\text { Con esos ojos y esas pestañas pareces mi burra comiendo } \\
\text { castañas }\end{array}$ \\
\cline { 2 - 2 } & $\begin{array}{l}\text { Tu madre debe ser pastelera, porque un bombón como tú no lo } \\
\text { hace cualquiera }\end{array}$ \\
\cline { 2 - 2 } & $\begin{array}{l}\text { El día que naciste hubo una lluvia de estrellas y en tu casa cayó } \\
\text { la más bonita de ellas }\end{array}$ \\
\hline \multirow{5}{*}{ (algunas hiperbólicas) } & Tía buena, maciza, tu culo me hipnotiza \\
\cline { 2 - 2 } & Eres un ángel caído del cielo \\
\cline { 2 - 2 } & Bombón, que se te ha caído el papel \\
\cline { 2 - 2 } & Eres una rosa bombón para otro bombón \\
\hline
\end{tabular}


ONOMÁZEIN 34 (diciembre de 2016): 322-350

Dimitrinka G. Níkleva:

Tendencias actuales en los piropos españoles

\begin{tabular}{|c|c|}
\hline & Tendrias que ser patrimonio de la humanidad \\
\hline & ¡Te comía tó, hasta el elástico del tanga! \\
\hline \multirow{4}{*}{ Comparaciones } & Tus ojos son como la miel \\
\hline & Estás más apretada que las tuercas de un submarino \\
\hline & Tienes más delantera que el equipo de Real Madrid \\
\hline & Eso es carne y no lo que mi madre echa al puchero \\
\hline Dilogías & Eso sí es un cuerpo y no el de la policía \\
\hline \multirow{4}{*}{ Personificaciones } & No sabía que los monumentos andaban \\
\hline & Guapa, que la luna te envidia cuando sale \\
\hline & Si paseas por la torre de Pisa hasta ella se endereza \\
\hline & Que no me entere yo que ese culo pasa hambre \\
\hline Superlativos & ¡Guapísima! \\
\hline \multirow{4}{*}{ Vocativos } & Niña,... \\
\hline & Morena, ... \\
\hline & Rubia, ... \\
\hline & Dios, ... \\
\hline \multirow{2}{*}{ Aumentativos } & morenaza \\
\hline & macizorro \\
\hline Condiciones irreales & Si la belleza fuese pecado, estabas condenada \\
\hline
\end{tabular}

En algunos de los ejemplos y de los piropos, en general, se combinan varios recursos expresivos.

\section{Conclusiones}

Sin duda, los piropos han cambiado notablemente en las últimas décadas. No son tan poéticos y románticos como de antaño; ya no piropean solo los hombres, sino también las mujeres - normalmente en condiciones intragrupales o en la intimidad - en un mundo cada vez más "unisex"; reflejan la vida moderna y su ritmo vertiginoso. El piropo es un 
ONOMÁZEIN 34 (diciembre de 2016): 322-350

Dimitrinka G. Níkleva:

Tendencias actuales en los piropos españoles

espejo de la sociedad que refleja los cambios lingüísticos y sociales, las normas de interacción y de cortesía, el papel de la mujer, entre otros. Por eso, consideramos que es necesario actualizar periódicamente las investigaciones sobre los piropos para observar los cambios producidos y las nuevas tendencias en cuanto a las características del piropeador y del piropeado, su edad, las situaciones del piropeo, la frecuencia de piropos dirigidos a mujeres en comparación con los dirigidos a hombres. Es muy interesante estudiar el estilo del piropo, su lenguaje, las características léxicas y morfosintácticas, además de los recursos expresivos utilizados.

Los estudios sobre el piropo se ubican en el marco de la pragmática y en concreto, de la cortesía-descortesía. Normalmente, no se trata de fórmulas cerradas, sino que se permite la creatividad. El piropo encierra actitudes no normativas, con frecuencia no corteses, pero aun así es positivo para el receptor. Podemos afirmar incluso que se agradece por parte de los piropeados. Coincidimos con Calvo Pérez (2005) en que las mujeres quedarían preocupadas si los hombres no las piropean y, sobre todo, si no lo hacen en situaciones y sitios donde el piropo es socialmente esperable.

Hay que recordar que el piropo tiene una función lúdica, principalmente que predomina sobre la poética, la apelativa y la expresiva o emotiva. Nuestro estudio ha confirmado que el piropo es hiperbólico por naturaleza y que combina una amplia variedad de recursos expresivos como la metáfora, la comparación y la personificación. Abundan los superlativos. Son frecuentes los vocativos, los diminutivos y los aumentativos.

En los piropos de hombres la palabra más frecuente es bombón, seguida por guapa y sol. Las mujeres prefieren guapo y bueno.

En cuanto a la categoría gramatical, los hombres emplean más sustantivos, seguidos por pronombres, verbos y adjetivos en cuarta posición, a diferencia de las mujeres que se inclinan por los adjetivos en segundo lugar.

Según la época y las características de la sociedad en concreto, el piropo ha servido para reforzar una cultura romántica, una cultura machista o una cultura de la tecnología y del ritmo vertiginoso de la vida moderna, tal como se confirma en nuestra investigación. 
ONOMÁZEIN 34 (diciembre de 2016): 322-350

Dimitrinka G. Níkleva:

Tendencias actuales en los piropos españoles

\section{Bibliografía citada}

Álvarez Quintero, Serafín y Joaquín, 1924: Teatro completo. Los piropos, Madrid: Imprenta Clásica Española.

ANDREWS, David, 1977: "Flirtation Walk-Piropos in Latin America", Journal of Popular Culture 11, 49-61.

BEINHAUER, Werner, 1978 [1929]: El español coloquial, Madrid: Gredos.

Calvo Carilla, José Luis, 2000. La palabra inflamada. Historia y metafísica del piropo literario en el siglo $X X$, Barcelona: Península.

CAlvo PÉREZ, Julio, 2005: "El piropo en España de 2000 y las nuevas formas de cortesía”, Revista Internacional de Lingüística Iberoamericana (RILI) vol. III, nº 1 (5), 31-47.

Carreras-Riudavets, F., J. C. Santana-Herrera, Z. Hernández-Figueroa, G. Rodríguez-Rodríguez, 2011: Parametrizador morfológico de textos - ParamText TIP [disponible en http://tip.dis.ulpgc.es].

DiOSDADO, Esteban, 1996: Los mejores piropos, Barcelona: Edicomunicación.

EnRíQueZ, David, 1991: Breve antología del piropo, Santiago de Chile: Ediciones Cerro Huelén.

Epton, Nina, 1965: El amor y los españoles (trad. de Ana María de la Fuente), Barcelona: Plaza y Janés.

FridzILIUS, Noemi, 2009: Me gustaría ser baldosa... Un estudio cualitativo sobre el uso actual de los piropos callejeros en España [disponible en https://gupea.ub.gu.se/bitstream/2077/21469/1/gupea_2077_21469_1.pdf].

LÓPeZ De Haro, Rafael, 1953: Piropo, Madrid: Cid.

Malaver, Irania y Carla GonZÁlez, 2008: "El antipiropo: el lado oculto de la cortesía verbal" en A. Briz y otros (eds.): Cortesía y conversación: de lo escrito a lo oral. III Coloquio Internacional del Programa EDICE, Valencia: Universitat de València, 267282.

Placencia, María E. y L. Mariana YÉPEZ, 1999: "Compliments in Ecuadorian Spanish", Lengua 9, 83-121. 
ONOMÁZEIN 34 (diciembre de 2016): 322-350

Dimitrinka G. Níkleva:

Tendencias actuales en los piropos españoles

PreISIG, Gabriela, 1998: Una investigación sobre el piropo español. Tesis doctoral. The University of British Columbia [disponible en https://circle.ubc.ca/bitstream/handle/2429/10018/ubc_1999-0078.pdf].

SHREIER, Judith, 2005: "Quién fuera mecánico...: un estudio sociopragmático sobre la aceptación del piropo”, Revista Internacional de Lingüística Iberoamericana 5, 65-78.

VenclovsKÁ, Natálie, 2006: Los piropos españoles [disponible en http://is.muni.cz/th/75447/ff_b/bakalinek.pdf].

ZvereVA, Ekaterina Vladislavovna [Зверева, Екатерина Владиславовна], 2014: Использование коппьютерной терминологии в испанских комплиментах (рігоров informáticos). Ponencia en la XLIII Conferencia Científica Filológica Internacional, 161-168 [disponible en http://www.conference-spbu.ru/conference/13/reports/350/].

\section{Anexos}

El cuestionario que se incluye a continuación fue anónimo y se dejó el suficiente espacio para responder (aquí se abrevia el espacio de las respuestas).

\section{CUESTIONARIO SOBRE EL PIROPO}

Fecha: Titulación:

Curso: Edad:

Sexo: Hombre Mujer

1. ¿Quién piropea a quién?

2. ¿Qué edad suele tener el piropeador?

3. ¿Qué edad suele tener el piropeado?

4. ¿Dónde se piropea?

5. ¿En qué situación se piropea?

6. ¿Sobre qué versa el piropo?

7. ¿Cuál es la situación más típica en que se produce o se espera un piropo? 
ONOMÁZEIN 34 (diciembre de 2016): 322-350

Dimitrinka G. Níkleva:

Tendencias actuales en los piropos españoles

8. ¿Cómo sueles reaccionar al piropo? ¿Contestas? ¿De qué manera?

9. La palabra piropo tiene sinónimos: cumplido, halago, lisonja, requiebro. ¿En qué se diferencian? Pon un ejemplo de cada uno.

Piropo. Definición.

Ejemplo:

Cumplido. Definición.

Ejemplo:

Halago. Definición.

Ejemplo:

Lisonja. Definición.

Ejemplo:

Requiebro.

Ejemplo:

10. ¿Gustan hoy los piropos? ¿En qué circunstancias?

11. ¿Se dicen hoy contrapiropos (frases devolviendo la pelota)?

12. ¿Ha evolucionado el piropo desde que tus padres eran jóvenes hasta el momento presente? ¿Cómo?

13. Pon ejemplos de piropos recibidos y hechos por ti. Haz los ejemplos como minidiálogos (incluyendo la respuesta del piropeado). Utiliza $\mathrm{M}$ (por mujer) y $\mathrm{H}$ (por hombre).

a) Piropos recibidos (por lo menos 5)

b) Piropos hechos (por lo menos 5)

14. ¿Te gustan los piropos? ¿Cuál es el que más te gusta? ¿Y el que menos? 